\title{
Will the enterprise performance be enhanced by reduction of perks of executives of the state-owned enterprises?
}

\author{
Xu Wang \\ Zhenjiang College, Zhenjiang, Jiangsu, China
}

\begin{abstract}
This paper carries out the quasi-experiment through the policy implementation of "eight provisions", and researches the relationship between the perks of the state-owned enterprises and enterprise performance. Before and after the policy implementation through the Difference in Differences (DID), compared with the private enterprises, the state-owned enterprise performance controlled by the local government is significantly declined after the policy implementation, because the perks becomes a way for the executives to obtain personal invisible welfare due to the regulation of the executive compensation of the state-owned enterprise. After the policy implementation of eight provisions, the executive incentive is limited, so that the state-owned enterprise performance e is also declined to a certain extent.
\end{abstract}

Keywords: perks; enterprise executives; state-owned enterprises; enterprise performance

\section{INTRODUCTION}

In recent years, the perks of the executives of the state-owned enterprises has repeatedly been exposed with serious waste problem, which has been widely criticized by the public. How to regulate the perks of the executives of the state-owned enterprises has always been valued by the government. In December 2012, the General Secretary, Xi Jinping proposed "eight provisions" and "six prohibitions" related to improving work style and maintaining close ties with the masses, and required that the administrative institutions and state-owned enterprises to strictly implement (although the real impact of the perks of the state-owned enterprises is "six prohibitions", but herein collectively referred to as "eight provisions"), thus suddenly reducing recreational activities at public expenses.

The perks involves in all aspects of the enterprise executive work. Does it improve the working efficiency for the enterprise, or is it not conducive to enhance the enterprise performance? In the case of regulation of the executive compensation of the state-owned enterprises by the central government, will the strict implementation of "eight provisions" enhance the enterprise performance? To answer these questions, this paper carries out the "quasi- experimental" research through the implementation of "eight provisions", and discusses whether the strict implementation of "eight provisions" will reduce the perks of the state-owned enterprises, or enhance the enterprise performance by the use of DID, with the policy implementation group of the state-owned enterprise controlled by the local government and the contrast group of the private enterprise. To reduce the biased error of the sample selection, this paper adopts the Propensity Score Matching (PSM) to do PSM-DID on the basis of matching with the state holding enterprises and private enterprises.

\section{THEORETICAL ANALYSIS AND HYPOTHESIS PROPOSAL}

The perks refers to the welfare obtained from the duty of manager, or the benefits from implementation of specific work (Wan Hualin, 2007), which forms two main viewpoints on the impact of the enterprise performance: agency concept and efficiency concept. The agency concept believes that there is a principal-agent relationship between the enterprise owners and management layer. Due to the interest-oriented difference and information asymmetry, the management layer may use their power to pursue personal enjoyment, excessive post-related consumption and other self-interested behaviors, thus damaging the decisions 
of owners' interests (Jensen and Meckling, 1976). Therefore, the perks is considered to be the agent cost of the enterprise, which has a negative impact on the enterprise value. For example, Yermack (2006) believes that the perks increases the private benefits of the management layer, but damages the shareholders' equity. The controlling shareholder of the state-owned enterprise in China is the state. However, due to multi-level relations of agency, the government is prone to "absence of owner" in the regulatory process, so it is difficult to effectively monitor the state-owned assets on behalf of the state, and safeguard the interests of state-owned property right. If the internal supervisory mechanisms of the state-owned enterprise are inadequate, the executives may use their power to pursue additional consumption, so that the agent cost of the enterprise is significantly higher than that of nonstate-owned enterprise. Chen Donghua, et al. (2005), $\mathrm{Lu}$ Rui, et al (2008) find that the perks of the state-owned enterprise has a significant negative correlation with the enterprise performance or enterprise value, but without correlation with non-state- owned enterprises.

The efficiency concept believes that, the perks has a reasonable positive side as an implicit incentive, which can improve work efficiency of the managers, and enhance the enterprise value. In the case of separation of two rights of corporate governance, in order to improve working enthusiasm of the managers, the owners achieve the maximization of the shareholder wealth, and the perks can generally reduce the internal organization cost of the enterprise. For example, Hirsch (1976) believes that luxury perks can bring spiritual and material satisfaction for the executives, which can effectively improve the management efficiency of the executives, and strengthen the status and authority of the executives (Rajan and Wulf, 2004). Adithipyangkul, et al. (2009) find that, the perks has a positive correlation with the future return on assets, which supports the viewpoint that the perks can improve the enterprise performance and play an incentive role. Chen et al. (2010) believe that, as an implicit compensation, the perks of the executives is the same with the monetary compensation, which plays a positive incentive role. The perks has a significant positive correlation with the current and future performance of the enterprise. Li Yan, et al. (2010), Jiang Fuxiu and Huang Jicheng (2011) also believe that, for the executives of the state-owned enterprise, as an implicit compensation, the perks creates a good working environment for the executives to work hard, which plays a stronger incentive role for the executives, and is also helpful for improving their work efficiency, and enhancing the enterprise performance.

Although the agency concept and efficiency concept are seemingly opposite, Wan Hualin (2007) believes that there is a certain internal logic consistency. The incentive way of the executives and the completeness of the corporate governance affects whether the perks is line with the agency concept or efficiency concept. In addition to the monetary consumption, stock ownership incentive and other explicit contracts, the incentive contract of the enterprise executive also includes the perks, insider trading profits, political promotion and other forms of implicit contracts. As an important component of the executive's implicit compensation contract, the perks is a special right enjoyed by the position of the enterprise executives (Chen Donghua, et al, 2010; Luo et al, 2011), which is equivalent to the explicit monetary compensation in a sense. Therefore, the impact of the perks on the enterprise performance is not evaluated in isolation, which shall be analyzed together with the executive compensation and other incentive ways.

Chinese government implements strict compensation regulation for the managers of the state-owned enterprises, especially after 2008, the effort of compensation limitation is constantly strengthened, so that the compensation of the management layer is unable to be self-regulated by the market, and the increase of the monetary compensation is limited. In order to obtain the maximum personal benefits, the executives of the state-owned enterprise view the perks as an alternative selection of the income of the managers (Xu et al., 2014). Therefore, the high consumption of the perks of the state-owned enterprises is directly related to the constraint of the compensation regulation. With respect to non-state-owned enterprises, there is not such an issue (Grove et al, 1995; Chen Donghua, et al, 2005). In the case of the compensation regulation of the executives of the state-owned enterprise, after strict implementation of "eight provisions" by the state-owned enterprise, the cost of perks should be significantly reduced, which may affect the enterprise performance. Therefore, according to the above analysis, this paper proposes the following alternative hypothesis:

Hypothesis 1a: The reduction of the perks level of the executive of the state-owned enterprise will reduce higher agent costs, so that the performance is increased compared with the performance of private enterprises (agency concept).

Hypothesis $1 \mathrm{~b}$ : In the case of the compensation regulation, the perks level of the state- owned enterprise is reduced, so that the performance is decreased compared with the performance of private enterprises (efficiency concept).

\section{RESEARCH METHODS AND SAMPLE SELECTION}

\subsection{Research methods}

DID is an important research method to assess the policy effectiveness, which is used widely in the domestic and foreign research due to reduction of the endogenous bias to some extent. Therefore, this paper 
also adopts DID to analyze whether the reduction of the perks is conductive to enhance the state-owned enterprise performance, and make analogy of the implementation of "eight provisions" as the quasi-experiment on a certain "treatment" applied by the test objects. The implementation of "eight provisions" is concentrated in the state-owned enterprises. The ownership structure of the state-owned enterprises supervised and managed by the central government is significantly different from that of the general private enterprises, the majority has a large scale and is often in a monopoly position of the industry, and the private enterprises are difficult to match with it. Therefore, we choose only the state-owned enterprises supervised and managed by the local governments as the policy impact group, and the private enterprises in the non-state holding enterprises as the control group to investigate the impact of "eight provisions" on the enterprise performance by DID. DID model is set as the formula (1):

$$
Y_{i t}=\beta_{0}+\beta_{1} S O E s_{i t}+\beta_{2} \text { Year }_{i t}+\beta_{3} D I D_{i t}+\beta_{4} X_{i t}+\varepsilon_{i t}
$$

$Y_{i t}$ is the explained variable, enterprise performance; SOEs are the enterprise groups of policy implementation, which are taken as 1 when they are local state-owned enterprises (treatment group), while taken as 2 when they are private enterprises (control group). The difference between the state-owned enterprise group and private enterprise group is expressed as $\beta_{1}$; the annual time variable is expressed as Year, of which the previous year of implementation of eight provisions is 1 , while the next year is 0 (that is, the value before 2013 is 0 , while the value after 2013 is 1 ); the interaction item $D I D$ (SOEs*Year) reflects the impact of policy on the enterprise performance. If "eight provisions" have a positive effect on the enterprise performance, the symbol of $\beta_{3}$ is significantly positive, otherwise it is negative. The factor that may affect the enterprise performance in the model can be as a control variable, $X_{i t}$.

The policy evaluation needs to satisfy two prerequisites by the use of DID: (1) the treatment group and the control group must satisfy the hypothesis of common trend. That is, before the implementation of "eight provisions", the change trend of the actual performance of the state-owned enterprise groups and private enterprise groups should have the same trend (see detailed analysis in Table 2). (2) The enterprise selection of the treatment group and control group is a random selection. Due to some inherent differences between two samples of the state-owned enterprises and private enterprises, in order to control this problem, we carry out matching selection of the samples of the control group through the propensity score matching (Heckman et al., 2010), and find out the private enterprises that are similar to the characteristics of the samples of the state-owned enterprises as the samples of the control group, so that the treatment group and control group have a certain degree of similarity before introduction of the policy, with comparability, and ensure that our evaluation has a smaller biased error, and finally estimate the policy effect by PSM-DID method.

\subsection{Sample selection}

The policy of "eight provisions" was enacted by the end of 2012, and the policy impact began from 2013. Therefore, this paper selects the data related to the listed companies before and after policy implementation from 2011 to 2014, and screens the samples in the following ways: (1) to delete the financial and ST, PT enterprises; (2) to delete the enterprises with incomplete data; (3) to delete the enterprises with changes in the nature of actual controller, namely, the enterprises with changes between the central state-owned enterprises, local state-owned enterprises and private enterprises; (4) to delete the state-owned enterprises supervised and controlled by the central government, but only research the state-owned enterprises and private enterprises supervised and controlled by the local governments. Finally, this paper obtains four years of data related to the effective samples of 3044 enterprises, and also carries out Winsor treatment of continuous variables at the level of $1 \%$. Except that the data of perks is acquired by the manual way, the data of other variables is from the GTA and CCER database.

\subsection{Variable selection}

As a kind of invisible benefit of the enterprise manager, the perks has not yet obtained a uniform measurement form. This paper views a total of eight costs, namely, the travel expense, business entertainment expense, communication expense, overseas training expense, car expense, office expense, board of directors' expense and conference expense in the foot-note to financial statements - "cash flow related to other operating activities" as the perks of the executives by the use of the methods of Chen Donghua et al. (2005). In order to avoid the impact of the enterprise size, this paper measures the perks by the use of the proportion of the sum of eight detailed costs and main business revenues (Perk) (Lu Rui et al., 2008).

The indicators measuring the enterprise performance are more and not uniform, and also have their shortcomings. In order to avoid the limitations of measurement with a single indicator, and preferably reflect the enterprise performance in a certain period, this paper refers to the methods of Liu Shaowei and Wan Dayan (2013) to select the enterprise value (Tobin's Q), return on equity (ROE), return on assets (ROA) and return on sales (TTM) and other indicators to establish comprehensive indicators of the enterprise performance (PEF), and also uses the principal component analysis method to measure the enterprise per- 
ICITCE 2015

Table 1. Annual changes of perks and executive compensation

\begin{tabular}{|l|l|l|l|l|l|}
\hline Item & Enterprise category & 2011 & 2012 & 2013 & 2014 \\
\hline \multirow{3}{*}{ On-duty compensation } & State-owned enterprise & 0.41 & 0.40 & 0.34 & 0.28 \\
\cline { 2 - 6 } & Private enterprise & 0.45 & 0.45 & 0.44 & 0.41 \\
\hline \multirow{2}{*}{ Executive compensation } & State-owned enterprise & 0.09 & 0.09 & 0.08 & 0.08 \\
\cline { 2 - 6 } & Private enterprise & 0.10 & 0.18 & 0.16 & 0.16 \\
\hline
\end{tabular}

Table 2. Changes of annual enterprise performance

\begin{tabular}{|l|l|l|l|l|}
\hline Annual performance of enterprise & 2011 & 2012 & 2013 & 2014 \\
\hline State-owned enterprise & 0.05 & -0.34 & -0.41 & -0.61 \\
\hline Private enterprise & 0.48 & 0.04 & 0.11 & 0.09 \\
\hline
\end{tabular}

formance of the principal component.

This paper adds the executive compensation (ExPay), enterprise size (Size), financial leverage (Lev), CEO duality (Dual), enterprise growth (Growth), board independence (DirRatio), enterprise rent (Rent), executive share (ExShare) and the degree of ownership concentration (Disp) and other control variables in the model.

\section{ANALYSIS OF EMPIRICAL RESULTS}

\subsection{Descriptive statistics}

Table 1 shows that the mean value of the perks of the state-owned enterprise is significantly reduced from 0.41 to 0.28 (2013), indicating that "eight provisions" have a significant impact on the perks of the state-owned enterprise, but little change for the private enterprises. The total amount of the perks of the state-owned enterprises is far more than that of the private enterprises, but the level of mean value is lower than that of the private enterprises (Dong Meisheng, 2012). Figure 2 shows that the government continues to limit the compensation of the executives of the state-owned enterprise, but the monetary compensation of the executives is not significantly reduced, and the change of annual mean value is little, with the same conclusion of Shen Yifeng and Li Peigong (2010). The expected effect of the "compensation limiting order" is not obvious, which is the same with the perks. The compensation of some executives of the state-owned enterprise is at a sky-high price, but the average level still has a certain gap with that of the private enterprises.

To calculate the comprehensive indicators of the enterprise performance PEF, this paper adopts the principal component analysis method to analyze four performance variable indicators - TobinQ, ROE, ROA and TTM. The test value of KMO is 0.7172 , and the statistics of Bartlett's sphericity test is 4252.6, indicating that there is a correlation between various indicators of measuring performance, which is more suitable for the principal component analysis. The characteristic root of the first principal component is 2.4 , greater than 1, while the characteristic root of the second principal component is less than 1 , so there is only a need to extract the first principal component, thus explaining $70.48 \%$ of the total variance. The first principal component is represented as the linear combination of various variables, so that the expression of the comprehensive indicators of the enterprise performance is as follows:

$$
\begin{aligned}
& \mathrm{PEF}=0.3651 * \text { TobinQ }+0.47 * \mathrm{ROE}+0.6092 * \mathrm{ROA}+ \\
& 0.5241 * \mathrm{TTM}
\end{aligned}
$$

The formula (2) can be used to calculate the value of each enterprise performance PEF. The mean values of the performance of the state-owned enterprises and private enterprises each year are shown in Table 2, which shows that the state-owned enterprise performance is worse than the private enterprise performance. Before policy implementation, the difference between the changes of the state-owned enterprise performance and the private enterprise performance is fixed in 2011 and 2012, and the change trends are basically the same, which are in line with the hypothesis of DID application. However, after 2012, there are different trends, of which the state-owned enterprise performance continues to decline, while the private enterprise performance basically remains unchanged.

\subsection{Model result analysis}

DID model results are shown in Table 3. DID coefficients of the interaction item of the model (1) (without controlling over other variables) and model (2) (controlling over other variables) are significantly negative indicating that eight provisions lead to decline of the state-owned enterprise performance. Year2013 and Year2014 of the model (3) analyze the changes in 2013 and 2014, and the coefficients are respectively -0.37 and -0.60 , which are reduced significantly. That is, the first year of the policy implementation significantly affects the enterprise performance, and even the second year also has a further impact, indicating that the central government constantly strengthens the implementation of eight provisions. To reduce the biased error of the sample selection, we use the kernel matching propensity score matching to construct a counter fact of the private enterprise that has a common supporting area with the state-owned enterprise, so that DID estimation results are more reliable. After 
kernel matching PSM matching through controlling over other variables, the number of samples after matching is 2510 , and DID estimation result is -0.245 , which is significantly negative at the level of $10 \%$ (see the model (4) in Table 3). It supports the hypothesis $1 \mathrm{~b}$ proposed previously, that is, the implementation of eight provisions reduces the state-owned enterprise performance.

To further analyze the impact of the perks of the state-owned enterprises on the performance, this paper adopts the grouping regression method to control over the industry and annual years in the regression model, and adopts White (1980) standard error to control over the heteroscedasticity. The results are shown in Table 4. The model (5) is the whole sample estimation, the models (6), (7), (8) are the samples of the state-owned enterprise, and the models (9), (10), (11) are the samples of the private enterprise. As can be seen from the table, the perks and enterprise performance do not have a significant correlation in the whole enterprise samples. However, the perks of the state-owned en- terprises in 2011 and 2012 and the enterprise performance have a significant negative correlation, and the coefficients after 2013 are insignificantly positive, indicating that, before introduction of the policy of "eight provisions", the perks of the state-owned enterprises and the enterprise performance have a negative correlation, and the perks declines the enterprise performance, but the reduction of the perks affects the enterprise performance after 2013. The private enterprise does not have change in the process of implementation of "eight provisions", and the perks and enterprise performance are insignificantly reverse.

\subsection{Robustness test}

This paper also tests the robustness of the empirical results through the following ways: (1) There is no difference between results by the use of the method of measuring the perks by the relative number of management expense ratio (James et al, 2000); (2) in terms of the performance measurement indicators, TobinQ,

Table 3. DID model results

\begin{tabular}{|c|c|c|c|c|}
\hline PEF & Model (1) & Model (2) & Model (3) & Model (4) \\
\hline Year & $\begin{array}{l}-0.16^{* *} \\
(-2.54)\end{array}$ & $\begin{array}{l}-0.09 \\
(-0.82)\end{array}$ & $\begin{array}{l}0.08 \\
(1.36)\end{array}$ & $\begin{array}{l}-0.13 * \\
(-1.75)\end{array}$ \\
\hline SOEs & $\begin{array}{l}-0.59 * * * \\
(-7.41)\end{array}$ & $\begin{array}{l}0.07 \\
(1.01)\end{array}$ & $\begin{array}{l}0.08 \\
(1.01)\end{array}$ & $\begin{array}{l}-0.36 * * * \\
(-4.38)\end{array}$ \\
\hline DID & $\begin{array}{l}-0.21^{*} \\
(-1.80)\end{array}$ & $\begin{array}{l}-0.48^{* * *} \\
(-2.79)\end{array}$ & & $\begin{array}{l}-0.245^{*} \\
(-1.67)\end{array}$ \\
\hline Year 2013 & $\begin{array}{l}-0.37 * * * \\
(-3.46)\end{array}$ & & & \\
\hline Year 2014 & $\begin{array}{l}-0.60 * * * \\
(-4.42)\end{array}$ & & & \\
\hline Control variables & No & Yes & Yes & Yes \\
\hline Adj-R2 & 0.09 & 0.31 & 0.33 & 0.03 \\
\hline Number of samples $(\mathrm{N})$ & 3044 & 3044 & 3044 & 2510 \\
\hline
\end{tabular}

Notes: T values, ${ }^{* * *},{ }^{* *}$ and $*$ in the brackets respectively represent that they are significant at the level of $1 \%, 5 \%$ and $10 \%$.

Table 4. Grouping regression model results

\begin{tabular}{|c|c|c|c|c|c|c|c|}
\hline & Whole samples & State-owne & nterprise & & Private ent & & \\
\hline & Model (5) & Model (6) & Model (7) & Model (8) & Model (9) & Model (10) & Model (11) \\
\hline & 2011-2014 & 2011-2014 & 2011-2012 & 2013-2014 & 2011-2014 & 2011-2012 & 2013-2014 \\
\hline Perk & 0.024 & -0.024 & $-0.111 * * *$ & 0.559 & -0.056 & -0.108 & -0.045 \\
\hline & $(0.60)$ & $(-0.53)$ & $(-4.10)$ & $(1.47)$ & $(-0.83)$ & $(-1.32)$ & $(-0.50)$ \\
\hline ExPay & $0.649 * *$ & $3.552 * * *$ & $1.844 * *$ & $3.365 * * *$ & $0.523 * *$ & $0.576^{*}$ & 0.630 \\
\hline & $(2.24)$ & $(3.06)$ & $(2.07)$ & $(2.82)$ & $(2.13)$ & $(1.70)$ & $(1.60)$ \\
\hline Lev & $-4.347 * * *$ & $-4.862 * * *$ & $-3.640 * * *$ & $-5.350 * * *$ & $-4.232 * * *$ & $-4.248 * * *$ & $-4.518 * * *$ \\
\hline & $(-10.39)$ & $(-5.27)$ & $(-6.94)$ & $(-4.66)$ & $(-11.62)$ & $(-11.01)$ & $(-9.50)$ \\
\hline Dual & 0.032 & 0.023 & 0.067 & -0.053 & -0.010 & -0.009 & -0.152 \\
\hline & $(0.50)$ & $(0.21)$ & $(0.57)$ & $(-0.30)$ & $(-0.13)$ & $(-0.11)$ & $(-1.40)$ \\
\hline Growth & $0.003 * * *$ & $0.008 * * *$ & $0.007 * * *$ & $0.005 *$ & $0.003 * * *$ & $0.002 * * *$ & $0.006 * * *$ \\
\hline & $(5.47)$ & $(3.08)$ & $(2.65)$ & $(1.75)$ & $(4.91)$ & $(2.88)$ & $(3.49)$ \\
\hline DirRatio & -0.019 & -0.055 & 0.099 & -0.100 & 0.026 & 0.039 & -0.011 \\
\hline & $(-0.50)$ & $(-0.85)$ & $(0.98)$ & $(-1.08)$ & $(0.59)$ & $(0.49)$ & $(-0.19)$ \\
\hline Rent & $-0.076 * * *$ & $-0.106 * *$ & -0.012 & $-0.163 *$ & $-0.070 * * *$ & $-0.036 * *$ & $-0.064 * * *$ \\
\hline & $(-4.62)$ & $(-2.30)$ & $(-0.73)$ & $(-1.94)$ & $(-5.20)$ & $(-2.19)$ & $(-4.01)$ \\
\hline ExShare & $0.002 *$ & -0.006 & 0.002 & 0.020 & $0.002 *$ & 0.001 & $0.003 * *$ \\
\hline & (1.84) & $(-0.59)$ & $(0.27)$ & $(1.26)$ & (1.88) & $(0.92)$ & $(2.05)$ \\
\hline Disp & 0.003 & 0.001 & 0.000 & 0.003 & 0.007 & 0.004 & 0.005 \\
\hline & $(0.81)$ & $(0.15)$ & $(0.11)$ & $(0.73)$ & $(1.58)$ & $(1.16)$ & (1.17) \\
\hline _cons & $-3.749 * * *$ & $-4.832 * *$ & $-4.901 * * *$ & $-4.731 * * *$ & $-5.138 * * *$ & $-5.534 * * *$ & $-4.9744 * * *$ \\
\hline & $(-2.96)$ & $(-2.16)$ & $(-2.66)$ & $(-2.11)$ & $(-3.19)$ & $(-3.63)$ & $(-2.86)$ \\
\hline Adj-R2 & 0.1844 & 0.2391 & 0.2525 & 0.2115 & 0.2166 & 0.2794 & 0.2247 \\
\hline $\mathbf{N}$ & 3044 & 1092 & 546 & 546 & 1952 & 976 & 976 \\
\hline
\end{tabular}


ROA, ROE, TTM are used for DID regression, and the result shows that ROA is not significant, but the other three are significantly negative, with the same conclusion; (3) this paper also uses PSM nearest neighbor matching method and radius matching method to match with two groups of enterprises based on the data in 2011 , so that various control variables are balanced in the distribution of the treatment group and control group, and the difference between the mean values of two groups of concomitant variables is less than $10 \%$, and then DID is used to make analysis, with the same conclusion. To sum up, the results are robust.

\section{CONCLUSION AND POLICY RECOMMENDATIONS}

This paper carries out the quasi-experimental research through the policy implementation of "eight provisions" by the use of DID, and finds that, compared with the private enterprise, the state-owned enterprise performance controlled by the local government is declined after implementation of "eight provisions". The perks level has a significant negative correlation with the state-owned enterprise performance before 2013, which is not conducive to enhance the performance, but the perks becomes a way for the executives to obtain personal invisible welfare due to the regulation of the compensation of the state-owned enterprise. After implementation of "eight provisions", the reduction of a portion of perks has an impact on the executive enthusiasm, so that the executive incentive is limited, and the performance is also declined compared with the private enterprise in the same period.

According to the above conclusions, we propose the following policy recommendations: (1) the perks has indispensability in the business operation process, which means that the perks is a double-edged sword, but it is not realistic to completely avoid the perks. Therefore, the state-owned enterprises should carry out sub-item management of the perks of the executives, and identify the expenses of the specific projects, in particular, restrict the enterprises with the specific industries, and reduce non-normal expenses of the perks. (2) In the case of the regulation of executive compensation of the state-owned enterprises, there is a need to improve the long-term performance evaluation mechanism, and refer to the design of the private enterprises, such as bonus, stock option, job promotion and other incentive ways of the executives, so that the incentive ways could not be unitary. Especially in the policy implementation of "eight provisions", there is a need to play a screening role of the external professional manager market, and select the competent managers as the executives of the state-owned enterprises. (3) Due to weakening of the supervision role of the enterprise ownership in the internal governance mechanism of the state-owned enterprise, and governance defects of the chairman and CEO, the supervision of the executive power is not in place. Therefore, the improvement of the internal governance mechanism of the enterprise can reduce unnecessary perks of the managers, and help protect the interests of the state and minority shareholders.

\section{REFERENCES:}

[1] Imbens G W, Wooldridge J M. 2008. Recent developments in the econometrics of program evaluation. Journal of Economic Literature, 47(1): 5-86.

[2] Rosenbaum P R, Rubin D B. 1983. The central role of the propensity score in observational studies for causal effects. Biometrika, 70(1): 41-55.

[3] Yermack D. 2006. Flights of fancy: Corporate jets, CEO perquisites, and inferior shareholder returns. Journal of Financial Economics, 80(1): 211-242.

[4] Chen Donghua, Chen Xinyuan, Wan Hualin. 2005. Compensation regulation and post compensation in the state-owned enterprises. Economic Research, (2): 92-101

[5] Lu Rui, Wei Minghai, Li Wenjing. 2008. Management power, post compensation and efficiency of property right-evidence from China's listed company. Nankai Business Review, (11): 85-92.

[6] Luo Hong, Huang Wenhua. 2008. Dividend, post compensation and enterprise performance of the state-owned enterprise. Management World, (9): 139-148.

[7] Rajan R G, Wulf J. 2004. Are perks purely managerial excess? Journal of Financial Economics, 79(1): 1-33.

[8] Adithipyangkul P, Alon I, Zhang T. 2009. Executive perks: Compensation and corporate performance in China. Asia Pacific Journal of Management, 28(2): 401-425.

[9] Chen Donghua, Liang Shangkun, Jiang Dequan. 2010. Cost and selection of executive incentive contract in different processes of marketalization: monetary compensation and perks. Accounting Research, 11: 56-64.

[10] Jiang Fuxiu, Huang Jicheng. 2011. Manager incentive, debt and enterprise value. Economic Research, 05: 46-60.

[11] Liu Shaowei, Wan Dayan. 2013. Executive compensation and enterprise performance: empirical comparative research of the state-owned and non-state-owned listed companies. China Soft Science, 2: 90-101.

[12] Feng Genfu, Zhao Juehang. 2012. Manager compensation, perks and enterprise performance based on the perspective of cooperative game analysis. China Industrial Economy, 06: 147-158.

[13] Wang Zeng, Fu Guoqun, Huang Danyang, Wang Jianfeng. 2014. Research on the relationship between "political promotion" and "perks" of the state-owned enterprise CEO. Management World, 05: 157-171.

[14] Wang Aiguo, Xu Xiangzhen. 2015. Executive compensation, perks, compensation gap and enterprise performance - empirical data from listed central management enterprises in Shanghai and Shenzhen in 2010 and 2012. Financial Research, 02: 48-56.

[15] Su Ran, Gao Minghua. 2015. Perks and enterprise performance: agency concept or efficiency concept - research based on the perspective of executive incentive. Journal of Shenzhen University (Humanities and Social Sciences), 02: 102-109. 